\section{Vancomicina en}

bacteriemias por

Staphylococcus

coagulasa negativa

y sobrevida en

recién nacidos.

No survival benefit

with empirical

vancomycin therapy

for coagulase-negative

staphylococcal

bloodstream infections

in infants. Ericson J,

Thaden J, Cross H,

Reese C, Fowler V,

et al. Pediatr Infect

Dis J 2015; 34: 371-5.
Introducción: Staphylococcus coagulasa negativa ( $\mathrm{SCN}$ ) es un agente frecuente de bacteriemias neonatales tardías en UCIN, las que pueden acompañarse de complicaciones a largo plazo y mayor estadía hospitalaria. En el enfrentamiento inicial empírico de estas infecciones habitualmente se emplea vancomicina, antimicrobiano asociado a la génesis de resistencia, infecciones posteriores por agentes resistentes y toxicidad renal y auditiva. El impacto del uso de vancomicina empírico en bacteriemias por SCN en neonatos es poco conocido, siendo este el objetivo del presente estudio.

Método: Evaluación retrospectiva de bacteriemias por SCN ocurridas en 348 UCIN en E.U.A. entre 1997 y 2012. Se incluyó sólo el primer episodio de bacteriemia, definido como dos hemocultivos (HC) positivos dentro de 4 días, tres positivos en 7 días o cuatro en 10 días. La administración de vancomicina desde el primer día de obtención del cultivo se consideró terapia empírica, y la administración después del primer a tercer día después de la toma del primer cultivo positivo se consideró tardía. Entre otros parámetros, se evaluó mortalidad a los 7 y 30 días del primer cultivo positivo.

Resultados: De una base de 887.910 pacientes se identificó a 4.364 (0,5\%) con bacteriemia por SCN; 2.848 (65\%) recibieron vancomicina empírica y $1.516(35 \%)$ recibieron terapia tardía. El 91\% del total de pacientes enrolados fueron $<$ de $1.500 \mathrm{~g}$ y no existió diferencias en la edad gestacional entre los grupos. Hubo diferencia significativa en la media de edad post-natal entre el grupo de inicio empírico versus tardío (14 versus 13 días). Luego del análisis multivariado la mortalidad a 30 días no mostró diferencia entre ambos grupos (OR 1,14 IC $95 \%$ 0,84-1,56). La mortalidad a los siete días y el egreso hospitalario tampoco mostró diferencias significativas entre los tratamientos tardíos versus empírico (OR 1,1 IC 0,67-1,82) y (OR 1,06 IC 0,81-1,39); respectivamente. El análisis de sensibilidad que incluyó pacientes con bacteriemia por SCN que recibieron cinco o más días de vancomicina después del cultivo positivo y aquellos que no recibieron vancomicina a pesar de tener HC positivos a SCN presentaron una mortalidad similar a 30 días (OR 0,96 IC 0,62-1,49). La duración media de la bacteriemia fue un día menos para quienes recibieron terapia empírica (tres días) comparado con los de inicio tardío (cuatro días, $\mathrm{p}<0,0001$ ). Por último, la estadía hospitalaria fue similar en ambos grupos, 78 días para el grupo de inicio empírico y 77 para los con vancomicina tardía $(\mathrm{p}=0,35)$.

Discusión: De frecuente indicación empírica en UCIN, con estudios previos que muestran que al menos 32\% de las indicaciones de vancomicina son inapropiadas, y conociendo las complicaciones ya mencionadas, parece relevante limitar su uso innecesario. Con los datos presentados, el inicio empírico sólo gana un día en la duración de la bacteriemia, no impacta la estadía hospitalaria y principalmente no mejora la mortalidad en situaciones de bacteriemia por SCN. Su indicación empírica debiera reservarse en situaciones epidemiológicas con alta prevalencia de SAMR. Aunque no se evalúan dosificaciones ni otras complicaciones a largo plazo, pareciera relevante replantear el inicio empírico de vancomicina al existir preponderancia de bacteriemias por SCN.

Conclusión: La terapia de inicio empírico con vancomicina en bacteriemias por SCN no mejora la mortalidad ni la estadía hospitalaria en pacientes de UCIN. La información presentada apoya una mejor decisión clínica acorde a la epidemiología local, balanceando los riesgos, limitando su uso frente a fuerte sospecha de SAMR, guiando su indicación según cultivos y susceptibilidad y reposicionando a la cloxacilina como antibioticoterapia en estas situaciones.

\section{Lecturas recomendadas}

1.- Sandoval A, Cofré F, Delpiano L, Izquierdo G, Labraña Y, Reyes A. Reposicionando la cloxacilina como antibioticoterapia empírica inicial en la sepsis tardía neonatal. Rev Chilena Infectol 2015; 32: 182-9.

2.- Chiu C H, Michelow I C, Cronin J, Ringer S A, Ferris T G, et al. Effectiveness of a guideline to reduce vamcomicyn use in the neonatal intensive care unit. Pediatr Infect Dis J 2011; 30: 273-8.

Luis Delpiano Hospital Clínico San Borja Arriarán

Correspondencia a: ludelpia@vtr.net 